\title{
JUSTIÇA TRANSICIONAL E A ONU
}

Tarciso Dal Maso Jardim ${ }^{1}$

\section{RESUMO}

O presente artigo enfoca os paradoxos da justiça transicional e os momentos históricos derivados das graves violações à dignidade humana ocorridas durante os regimes autoritaristas e totalitaristas durante o século XX. Essas experiências de violações resultantes de crimes de guerra hediondos catalisaram a criação dos tribunais internacionais, assim como a elaboração de novos padrões jurídicos, normas consuetudinárias e o desenvolvimento do direito internacional. Nessa construção, a ONU possui papel chave no sentido de legalizar o sistema internacional, punindo criminosos e indenizando vítimas.

Palavras-chave: Justiça Transicional; Direitos Humanos; Crimes de Guerra; Tribunais Penais;

\begin{abstract}
The aim of this article is to emphasize the transitional justice, as well as the historical moments inflicted by violent aggressions to human dignity during the authoritarian and totalitarian regimes in the XX century. Those violation experiences which resulted upon crimes of war speed up the creation of the international courts of justice, the elaboration of new legal patterns, new legal norms, which became very important for the development of the international law. In this way, the United Nations placed a key role in legalizing the international system, punishing the criminals and paying for the damages suffered by the war victims.
\end{abstract}

Key-words: transitional justice, human rights, war crimes, courts of justice.

\section{Justiça transicional}

1. As concepções ordinárias de justiça estatal são desafiadas na sua pretensa autosuficiência em situação de profunda transição política, quando se deseja enfrentar juridicamente crimes internacionais ${ }^{2}$ cometidos em regime político pretérito. É o que ocorre, por exemplo, em momentos históricos derivados de processo de paz ou de

\footnotetext{
${ }^{1}$ Professor no Curso de Relações Internacionais do Centro Universitário de Brasília e Consultor Legislativo do Senado Federal.

${ }^{2}$ Para efeito desse estudo serão considerados como crimes internacionais os passíveis de serem julgados pelo Tribunal Penal Internacional, nomeadamente o genocídio, os crimes contra a humanidade e os crimes de guerra. O crime de agressão também consta no Estatuto de Roma do Tribunal Penal Internacional, embora dependa de futura definição e de debate político com as Nações Unidas.
} 
superação de autoritarismo ou de totalitarismo ${ }^{3}$. Nesse contexto, surge debate em torno das possibilidades, dos limites, das virtudes e dos paradoxos da justiça transicional. $\mathrm{O}$ conceito de justiça transicional e seus contornos na práxis têm sido consideravelmente debatidos nos últimos anos, embora sem reflexo doutrinário significativo no Brasil. A justiça transicional é aquela realizada em mudanças políticas expressivas e que pretende enfrentar as violações graves à dignidade humana ocorridas em governo anterior ${ }^{4}$.

2. Segundo Naomi Roth-Arriaza ${ }^{5}$, a resposta a crimes violentos cometidos em período passado depende de fatores socioeconômicos, militares e de política interna, mas a influência internacional joga papel crescente nesse processo. E, reciprocamente, os esforços internacionais são influenciados pelas tentativas internas. Naomi analisa essa reciprocidade em três áreas: 1. impacto da atividade internacional e transnacional (seja por órgãos internacionais, seja pela influência das redes transnacionais de ativistas de direitos humanos) sobre cortes nacionais, comissões de verdade, reparações e discursos políticos sobre o passado; 2 . exercício da jurisdição universal ${ }^{6} ; 3$. estabelecimento de tribunais internacionais e de Comissão de Verdade por instâncias internacionais (como ocorreu em El Salvador) ${ }^{7}$.

3. Nesse quadro, normas ou instituições internacionais potencialmente estimulam ou realizam justiça transicional, devendo ser mais bem estudadas nesse prisma. Jon Elster aponta quatro níveis de realização da justiça transicional: instituições supranacionais, Estados, atores corporativos e indivíduos ${ }^{8}$. O autor, ao mencionar supranacionalidade, envolve principalmente instituições intergovernamentais, como é o caso do tribunal penal internacional permanente, mas não propriamente organismos supranacionais.

\footnotetext{
3 Tucker aponta três tipos de transição: restauração democrática, transição após longo período de autoritarismo e transição pós-totalitarismo. TUCKER, Aviezer. Paranoids may be Prosecuted: posttotalitarism retroactive justice. In Archives Européenes de Sociologie, n. 40 (1), 1999, p. 56.

4 A justiça transicional também é associada à formação de cultura política democrática e de responsabilidade após experiências de violações generalizadas de direitos humanos. Por exemplo: TOIT, André du. Los Fundamentos Morales de las Comisiones de Verdad. La Verdad como Reconocimiento y la Justicia como Recognition: Principios de la Justicia Transicional en la Práctica de la Comisión de Verdad y Reconciliación (CVR) Sudafricana. In 18 Ensayos: Justicia Transicional, Estado de Derecho y Democracia. Chile: Universidad de Chile, 2005. Disponível em: http://www.publicacionescdh.uchile.cl/Libros/18ensayos.html. Acesso em: 20 de outubro de 2005.

${ }^{5}$ ROTH-ARRIAZA, Naomi. The role of international actors in national accountability processes. In BRITO, Alexandra Barahona; GONSÁLEZ-ENRÍQUEZ, Carmen; AGUILAR, Paloma. The Politics of Memory: transitional justice in democratizing societies. Oxford: Oxford studies in democratization, 2001, pp. 40-1.

${ }^{6}$ Justiça universal é aquela que permite julgar qualquer acusado, independente de sua nacionalidade ou da vítima, ou do território onde fora cometida a conduta criminosa. Esse poder é dado por vários tratados internacionais, como os relacionados à tortura e aos crimes de guerra.

${ }^{7}$ A Comissão de Verdade foi estimulada pelos bons ofícios do Secretário Geral da ONU nos acordos de paz negociados e firmados entre 1989 e 1992. Mais precisamente, a Comissão é criada nos Acordos do México (Cidade do México, 27 de abril de 1991) e ampliada nos Acordo de Paz de Chapultepec (16 de fevereiro de 1992).

${ }^{8}$ ELSTER, Jon. Closing the books: transitional justice in historical perspective. Cambridge: Cambridge University Press, 2004, p. 93 e seguintes.
} 
4. De qualquer forma, a repressão a certas condutas internacionalmente relevantes está intimamente ligada à intensificação das relações econômicas e sociais entre povos e, por via de consequiência, ao surgimento de organizações intergovernamentais de vocação universal. Historicamente, essa constatação é evidenciada pela evolução da noção de crime internacional da pirataria ou da escravidão ${ }^{9}$, mas não há dúvida que é em torno dos crimes de guerra que ela é consolidada.

\section{Justiça transicional e a Liga das Nações}

5. Como mencionado, a definição de crimes de guerra catalisou as primeiras experiências de julgamento internacional. Essa tipificação é produto de normas consuetudinárias internacionais e do desenvolvimento do direito internacional dos conflitos armados, que teve sua primeira sistematização internacional nas duas Conferências da Paz da Haia, em 1899 e 1907, e seu ápice nas quatro Convenções de Genebra de 1949, que foram aperfeiçoadas pelos dois Protocolos adicionais de 1977 e por vários tratados sobre meios e métodos de combate. Entretanto, se é verdade que os crimes de guerra impulsionaram os primeiros passos da justiça internacional penal, igualmente em torno deles são registrados os primeiros fracassos de uma organização intergovernamental na busca da justiça.

6. Essa referência diz respeito às tentativas da Liga das Nações, que não conseguiu julgar os grandes criminosos da Primeira Grande Guerra, apesar de o Tratado de Versalhes ter consagrado normas a respeito. O próprio Estados Unidos opunha-se à idéia de estabelecimento desses julgamentos, em razão de acreditar que possuíam característica de justiça ex post facto e que a questão seria de moralidade, não de direito. Mesmo assim, o art. 227 do Tratado de Versalhes previu o julgamento do kaiser Wilhelm II de Hohensollern, por ofensa suprema contra a moralidade internacional e a santidade dos tratados. O tratado previu a criação de tribunal internacional para julgá-lo, que jamais foi instalado, pois o kaiser recebeu asilo nos Países Baixos, que, posteriormente, negou pedido de extradição por considerá-la fundada em norma penal retroativa. Por ironia histórica, o kaiser Wilhelm morreu em 1941, justo no ano em que Alemanha invade os Países Baixos ${ }^{10}$.

7. Os arts. 228-230 do Tratado de Versalhes previram que os alemães poderiam ser julgados por crimes de guerra por qualquer dos Estados aliados. A Alemanha não aceitou essas disposições e acordou que houvesse listagem de acusados para serem julgados em seu próprio território. Essa lista iniciou com 900 pessoas, passou para 40 e terminou em $12^{11}$. Foram os julgados de Leipzig, cujos casos mais famosos dizem respeito a ordens manifestante ilegais ${ }^{12}$.

\footnotetext{
${ }^{9}$ BASSIOUNI, Cherif. Crimes Against Humanity in International Criminal Law. Hague: Kluwer Law International, 1999, p. 515-17.

${ }^{10}$ SCHABAS, William. An Introduction to the International Criminal Court. Cambridge: Cambridge University Press, 2001, p. 3.

${ }^{11}$ SCHABAS, William. Ibidem, p. 4.

${ }^{12}$ CASSESE, Antonio. International Criminal Law. New York: Oxford University Press, 2003, p. $234-5$.
} 
8. No Llandovery Castle, em 1921, a Suprema Corte de Leipzig admitiu a ordem superior como atenuante para dois tenentes, que seguiam ordens do governo alemão de afundar todo navio-hospital por suspeita de transporte de militares e atacaram navio-hospital inglês, inclusive seus botes salva-vidas, para evitar testemunhas. No mesmo contexto, no caso Dover Castle, também julgado pela mesma Corte de Leipzig, dois limites foram apontados para a obediência hierárquica como defesa: quando o subordinado ultrapassa a ordem dada ou sabe que a ordem é contrária ao direito. ${ }^{13}$ Independentemente dessa jurisprudência, pelos poucos julgamentos e pelos atores secundários que foram julgados, pode-se afirmar que em matéria de responsabilização penal a experiência pós-Primeira Guerra não obteve sucesso.

9. Como reforço desse insucesso, pode ser citada a intenção de julgamento dos turcos pelo massacre dos armênios, também durante a Primeira Guerra. Essa tentativa deu-se mediante o Tratado de Sèvres, de 1920, que jamais foi ratificado pela Turquia. O art. 226 do Tratado de Sévrès concedeu às Potências Aliadas o poder de julgar os turcos que cometeram crimes de guerra durante a Primeira Guerra Mundial. E o art. 230 aventou a possibilidade de tribunal ser criado pela Liga das Nações para esse efeito. Essas pretensões foram fracassadas, e definitivamente afastadas pelo Tratado de Lausanne de 1923, que "anistiou" os turcos. ${ }^{14}$

10. Em 1937, a Liga das Nações apresenta projeto de convenção de corte penal internacional, sem sucesso, embora tenha servido de base para o futuro tribunal de Nuremberg, que é concebido durante o curso das hostilidades da Segunda Guerra. Conforme Declaração de Moscou de $1^{\circ}$ de novembro de 1943, os Aliados afirmaram sua disposição de julgar os nazistas, o que é reconhecido no preâmbulo do "Agreement for the Prosecution and Punishment of the Major War Criminals of the European Axis, and Charter of the International Military Tribunal", que entrou em vigor em 8 de agosto de $1945^{15}$.

\section{Justiça transicional na era ONU}

11. Segundo Ruti Teitel, somente na era ONU há, de fato, a primeira experiência contemporânea de justiça transicional. A autora, em discussão sobre a genealogia da justiça transicional ${ }^{16}$, aponta três fases históricas modernas desse tipo de justiça ${ }^{17}$. A primeira fase histórica é o período posterior à Segunda Guerra Mundial, de tom internacionalista, quando se instalaram os tribunais penais de Nuremberg e de Tóquio. A opção internacional do pós-guerra, segundo Teitel, está relacionada ao desfecho insatisfatório da Primeira Guerra Mundial, quando as soluções de justiça nacional foram falhas (e.g., julgamentos em Leipzig e na Turquia) e as coletivamente imputadas foram desastrosas, como as estabelecidas para a Alemanha pelo trabalho de Versalhes.

\footnotetext{
${ }^{13}$ McCORMACK, Timothy. From Sun Tzu to the Sixth Committee: the evolution of an International Criminal Law. In McCORMACK, Timothy; SIMPSON, Gerry. The Law of War Crimes: national and international approaches. Hague: Kluwer Law International, 1997, p. 48-50

${ }^{14}$ SCHABAS, William. Op. Cit., p. 4; McCORMACK, Timothy, loc. cit., p. 48.

${ }^{15}$ SCHABAS, William. Ibidem, p. 5.

16 TEITEL, Ruti. “Transitional Justice Genealogy”. In Harvard Human Rights Journal, Vol. 16, Spring 2003, Cambridge, MA, pp. 69-94.

${ }^{17}$ Ver também TEITEL, Ruti. Transitional Justice. New York: Oxford University Press, 2000.
} 
12. Contudo, não se pode esquecer que, após a Primeira Guerra Mundial, igualmente foram falhas as tentativas internacionais de julgamento, seja a pretendida pelo próprio tratado de Versalhes (em especial, julgar o kaiser Wilhelm II de Hohenzollern) ou pelo tratado de Sévrès, de 1920 (para julgar os "jovens turcos" pelo massacre dos armênios). $\mathrm{E}$, assim como é verdade que a perspectiva internacional foi contemplada após a Primeira Guerra mundial, embora com insucesso, também não se pode esquecer que houve atuação da justiça nacional após a Segunda Guerra Mundial. Não há dúvida, apesar dessas considerações, que Nuremberg estabelece as bases do direito internacional penal, mas sua existência merece melhor debate, não atrelado somente à Primeira Grande Guerra. Por exemplo, a construção normativa do direito internacional dos conflitos armados a partir da década de 60 do século XIX deve ser mais bem compreendida, especialmente no que se refere à delineação de crimes de guerra.

13.A segunda fase histórica apontada por Teitel é a do pós-Guerra Fria, principalmente a partir de 1989, quando houve o desmantelamento da União Soviética. Esse período é marcado por processos de democratização no Leste Europeu, na América Latina e na África. Nessa segunda fase, apesar da incidência de certo internacionalismo, a concepção de justiça esteve associada à idéia de reconstrução nacional e, muitas vezes, é particularista ou localista.

13. Vários países não privilegiaram a responsabilidade penal dos criminosos de antigo regime, optando-se freqüentemente por apuração da verdade ou outras formas de resposta aos fatos. Descortina-se nessa fase a justaposição entre verdade e justiça, em modelo restaurativo, como ocorreu em El Salvador por gestão do Secretário Geral da ONU. Nesse modelo a verdade é considerada de modo amplo (não individualizada, como no processo penal). Teitel compreende as comissões de verdade mais como processo de consolidação da paz e da reconstrução da identidade política, guardando relação com o processo penal pela função dissuasória, do que como construtora da memória e realizadora da justiça. Na realidade essa postura é contraditória, pois parte do pressuposto de conflito crítico entre paz, justiça e memória; enquanto cremos que é na ausência das comissões de verdade e no predomínio de auto-anistias, contrariamente, que poderia ser argüida a tensão da paz com a justiça e a memória.

14. A terceira fase, do fim do século XX até nossos dias, segundo Ruti Teitel, está ligada a condições atuais de conflito persistente (pequenos conflitos, Estados fracos, conflito permanente, etc.), que, diante instabilidades políticas, concebem como normal e contínuo um direito pensado para a violência. ${ }^{18}$ Como símbolo dessa percepção está a constituição do Tribunal Penal Internacional permanente em 1998, tendo seu Estatuto entrado em vigor em 2002. Esse Tribunal funda-se sobre a base da complementaridade entre a justiça internacional e as justiças nacionais, o que tem obrigado os Estados Partes a adaptarem suas legislações para poderem julgar qualquer crime de genocídio, crimes contra a

18 TEITEL, Ruti. “Transitional Justice Genealogy”. In Harvard Human Rights Journal, Vol. 16, Spring 2003, Cambridge, MA, pp. 69-94. 
humanidade e crimes de guerra, mesmo se não cometidos em seu território ou por seus nacionais. ${ }^{19}$

15. Segundo Teitel, essas possibilidades de justiça podem provocar transição política em determinado País. Isso em parte se confirma pela experiência no sistema interamericano de direitos humanos, sistema consolidado na década de 80 do século XX, que, mediante dois casos ("Tribunal Constitucional" ${ }^{20}$ e "Ivcher Bronstein",21, ambos contra o Peru), colaboraram com a queda do Presidente peruano Alberto Fujimori.

16. Além disso, Teitel argumenta que essa continuidade ou normalidade de justiça transicional é aplicável aos conceitos de intervenção humanitária e guerra preventiva. Essa não é a opinião aqui defendida, pois esses conceitos fazem parte, principalmente, de doutrina unilateral estadunidense que afrontam o direito internacional e, especificamente, a Carta das Nações Unidas. De qualquer forma, fiquemos com a agradável idéia de que a verdade pode ter papel contínuo na resposta a atrocidades contra a dignidade humana, sem perder a suspeita em "cosmopolistismo" de tom utilitarista.

17. Na esteira da percepção de justiça contínua ou tomada pela normalidade, não se pode ignorar o esforço de alguns autores em desmistificar a especificidade da justiça transicional, em relação à justiça ordinária. Posner e Vermeule, por exemplo, partem de duas premissas para atenuar a diferença entre a justiça ordinária e a transicional: 1. os teóricos da justiça transicional equivocam-se por tratar o regime de transição como objeto em si e, em razão disso, negam a relevância ou utilidade das comparações e analogias entre transições políticas e a multiplicidade de transições que ocorrem em democracias consolidadas; 2. e, se a justiça transicional é a continuação da justiça ordinária, não há razão para tratar as medidas tomadas durante justiça transicional como não confiáveis ${ }^{22}$.

18. Particularmente, defendemos a especificidade da justiça transicional e sua forma de trabalhar com atos simbólicos, comissões de verdade e medidas de "purificação" (como as confissões em troca de anistia e a proibição do não exercício de funções públicas aos culpados pelas atrocidades do passado ${ }^{23}$. Transversalmente, o resgate ou a construção da memória coletiva assume função primordial na transição política. Esse resgate/construção transcende a concepção de justiça transicional como sendo dirigida somente ao passado, punindo criminosos ou indenizando vítimas. ${ }^{24}$

19. Nessa construção, a ONU possui papel chave e não deve ser ignorada essa função no debate sobre a reforma de sua Carta. Não podemos esquecer que os princípios de

\footnotetext{
${ }^{19}$ É a concepção da jurisdição universal.

${ }^{20}$ Sentença de 31 de janeiro de 2001.

${ }^{21}$ Sentença de 6 de fevereiro de 2001.

${ }^{22}$ POSNER, Eric A.; VERMEULE, Adrian. Transitional Justice as Ordinary Justice. In Harvard Law Review, volume 117, January 2004, n. 3, pp. 763-4.

${ }^{23}$ Discussão mais fortemente instalada na Europa do Leste, nos processo pós-comunismo. Ver, por exemplo, BORNEMAN, John. Settling Accounts: violence, justice, and accountability in postsocialist Europe. Princeton: Princeton University Press, 1997.

${ }^{24}$ POSNER, Eric A.; VERMEULE, Adrian. Transitional Justice as Ordinary Justice. In Harvard Law Review, volume 117, January 2004, n. 3, pp. 766.
} 
Nuremberg foram transformados em resolução pela Assembléia Geral da ONU (res. 95 I, de 11 de dezembro de 1946), que os Tribunais Penais Internacionais para a ExIugoslávia e para Ruanda foram criados pelo Conselho de Segurança da ONU, que a ONU impulsionou a criação de tribunais especiais mistos, como o de Serra Leoa; gestões desse organismo culminaram na constituição do Tribunal Penal Internacional permanente, em julho de 1998, e que o Conselho de Segurança pode remeter a este organismo qualquer caso para julgamento, mesmo se o Estado onde foi cometido o crime não ratificou o Estatuto de Roma do TPI, o que já ocorreu em março de 2005, com a submissão do caso de Darfur (Sudão).

20. Nesse marco onusiano, a Conferência de Viena de $1993^{25}$, ao versar sobre método de implementação e monitoramento do Programa de Ação e da Declaração de Viena (II.E, item 91), apontou a preocupação com a impunidade dos responsáveis por violações de direitos humanos, apoiando os esforços da Comissão de Direitos Humanos e da SubComissão sobre Prevenção de Minorias para examinar todas os aspectos da questão. Além disso, propugna à Comissão de Direitos Internacional da ONU para continuar seu trabalho sobre o tribunal penal internacional (II.E, item 92), que foi consolidado em julho de 1998.

21. Já na Conferência de acompanhamento dos resultados da Conferência de Viena, em 11 de setembro de 1998 (A/53/372), o Secretário Geral da ONU, encaminha à Assembléia Geral o relatório do Alto Comissário das Nações Unidas para Direitos Humanos. Esse documento reconhece no item 75 / IX que, textus:

"75. (...) The Dayton Agreement, the activities of the Truth and Reconciliation Commission in South Africa and the truth commissions in some Latin American countries all bear witness to the practical dimension of this approach. The establishment of International Tribunals for the former Yugoslavia and Rwanda, as well as the adoption of the Statute for the International Criminal Court by the International Diplomatic Conference in Rome on 17 July 1998 indicate progress in line with the recommendations made by the World Conference (sect. II, para. 96). These developments provide additional evidence that the international community is determined to hold all individuals, regardless of official rank or capacity, responsible for committing such horrific crimes as genocide, war crimes and crimes against humanity. The question of impunity has been the subject of study by the Subcommission on the Prevention of Discrimination and Protection of Minorities. Two reports have been prepared on the impunity of perpetrators of human rights violations: one in the area of civil and political rights and the other concerning economic, social and cultural rights."

22. Podemos frisar do excerto de relatório exposto vários pontos úteis para o objeto do presente estudo, tais como a amplitude da perspectiva de justiça buscada, não concentrada somente na punição criminal, pois avança na necessidade de busca da verdade, bem como está preocupada com todas as categorias de direitos humanos violados, não esquecendo dos direitos econômicos, sociais e culturais. Outro ponto a ser

${ }^{25}$ A/CONF.157/23, de 12 de julho de 1993. 
destacado é a função de aperfeiçoamento da justiça internacional atribuída à Subcomissão para a Prevenção de Discriminação e Proteção de Minorias, a partir de 1999 intitulada Subcomissão sobre Promoção e Proteção dos Direitos Humanos, que foi o principal órgão de apoio à Comissão de Direitos Humanos da ONU, hoje transformada em Conselho de Direitos Humanos.

\section{ONU, justiça transicional e a construção da memória}

23. Em relatório do Secretário Geral da ONU sobre a reforma do sistema (A/59/2005), chamado In larger freedom: towards development, security and human rights for all, dispõe:

"138. Justice is a vital component of the rule of law. Enormous progress has been made with the establishment of the International Criminal Court, the continuing work of the two ad hoc tribunals for the former Yugoslavia and Rwanda, and the creation of a mixed tribunal in Sierra Leone and hopefully soon in Cambodia as well. Other important initiatives include commissions of experts and inquiry, such as those set up for Darfur, Timor-Leste and Côte d'Ivoire. Yet impunity continues to overshadow advances made in international humanitarian law, with tragic consequences in the form of flagrant and widespread human rights abuses continuing to this day. To increase avenues of redress for the victims of atrocities and deter further horrors, I encourage Member States to cooperate fully with the International Criminal Court and other international or mixed war crimes tribunals, and to surrender accused persons to them upon request."

24. O Secretário Geral da ONU encoraja, portanto, a justiça penal internacional. Um dos temas caros a essa forma de justiça é a reparação às vítimas. Criados pelo Conselho de Segurança da ONU, os tribunais penais internacionais ad hoc são tímidos na contemplação dessa reparação, embora o Estatuto do Tribunal Penal Internacional para a Ex-Iugoslávia preveja, no art. $24, \S 3^{\circ}$, a possibilidade de a primeira instância determinar a restituição a seus proprietários legítimos de todos os bens e recursos adquiridos de modo ilícito, incluindo por meios coercitivos. O Tribunal de Ruanda, art. $23, \S 3^{\circ}$, possui disposição idêntica. Importa destacar, também, as Regras 105 e 106 do Regulamento processual do Tribunal para a Ex-Iugoslávia, que estabelece formas de compensação. ${ }^{26}$

25. O Tribunal Penal Internacional permanente aperfeiçoou, entre suas muitas inovações, o sistema de reparações às vítimas, que podem ser feitas por restituição, indenização ou reabilitação. $^{27}$ Esse modelo é igualmente emblemático por trabalhar com a responsabilidade penal individual, transpondo outro necessário viés da justiça, distinto do foco estatal. Além disso, importa lembrar que um modelo de justiça penal agregada à

\footnotetext{
${ }^{26}$ CASSESE, Antonio. International Criminal Court. New York: Oxford University Press, 2003, p. 429.

${ }^{27} \mathrm{O} \S 1^{\circ}$ do art. 75 do Estatuto de Roma do TPI determina que: 1. O Tribunal estabelecerá princípios aplicáveis às formas de reparação, tais como a restituição, a indenização ou a reabilitação, que hajam de ser atribuídas às vítimas ou aos titulares desse direito. Nesta base, o Tribunal poderá, de ofício ou por requerimento, em circunstâncias excepcionais, determinar a extensão e o nível dos danos, da perda ou do prejuízo causados às vítimas ou aos titulares do direito à reparação, com a indicação dos princípios nos quais fundamentou a sua decisão.
} 
reparação a vítimas é ideal para explorar a tese de que o direito penal tem sido utilizado como espécie de mote interpretativo da história, o que tem impacto na formação da solidariedade social ${ }^{28}$. Não podemos esquecer, inclusive, que a fórmula adotada no art. 75 do Estatuto de Roma deve-se fortemente ao papel relevante das reparações no processo de reconciliação nos locais onde ocorreram as violações. ${ }^{29}$

26. Todavia, a fórmula do Estatuto de Roma é criticada por estar bastante concentrada nas posses do condenado e em doações incertas a Fundo de reparação. Rafaelle Maison ainda aponta as dificuldades reparatórias diante a prisão de criminosos menores, como o ocorrido na jurisprudência da Ex-Iugoslávia, que levaria a restritos beneficiários. ${ }^{30}$ Além disso, frisa que o agente criminoso nem sempre possui recursos suficientes para a reparação, em geral de natureza coletiva, e que tampouco serão alcançados bens em nome do Estado, por exemplo, que foram por ele expropriados. Dessa forma, nem mesmo o Fundo de Reparação às Vítimas (art. 79 do Estatuto de Roma) será suficiente para satisfazer o coletivo de vítimas, restando o sistema clássico da responsabilidade internacional do Estado mais protetor. Sugere a autora que a Assembléia Geral dos Estados Partes do Estatuto de Roma do TPI deveria criar modo de bens estatais alimentarem esse Fundo. Quando órgãos estatais estejam envolvidos, poderiam ser obrigados a repassar bens para o Fundo, com ajuda do Conselho de Segurança, a exemplo do que ocorreu no Iraque. ${ }^{31}$ A depender de como será gerado esse Fundo, poderemos traçar algum prognóstico para o futuro da reparação internacional ex delicto ${ }^{32}$. A Regra 98 do Regulamento Processual ${ }^{33}$ do TPI permite que sejam utilizadas verbas de agências intergovernamentais, internacionais e nacionais. Entretanto, por reação dos defensores da soberania estatal, foi incluído no parágrafo $4^{\circ}$ dessa Regra a necessidade de prévias consultas com o Estado interessado para viabilizar o repasse dos recursos dessas agências. $^{34}$

27. Cherie Booth aponta como outra função do Tribunal Penal Internacional a de construir a verdade, principalmente por sua potencialidade de criar relato objetivo e imparcial dos fatos. A autora não deixa de reconhecer que há limites de relatar a história

\footnotetext{
${ }^{28}$ Inspirado em Durkheim, Mark Osiel tem trabalhado essa perspectiva de construção da memória coletiva mediante atividades penais. Ver OSIEL, Mark. Making Public Memory, Publicly. In HESSE, Carla; POST, Robert. Human Rights in Political Transitions: Gettysburg to Bosnia. New York: Zone Books, 1999, pp. 217- 261.

${ }^{29}$ MUTTUKUMARU, Christopher. Reparation to Victims. In LEE, Roy. The International Criminal Court: the making of the Rome Statute. Hague: Kluwer Law International, 1999, p. 263.

${ }^{30}$ MAISON, Rafaelle. La Responsabilité individuelle pour crime d'état en Droit International Public. Editions Bruylant / Editions de 1Université de Bruxelles, 2004, p. 505.

${ }^{31}$ MAISON, Rafaelle. Op. cit., p. 506-7.

${ }^{32}$ BOURDON, William. La Cour pénale internationale. Paris : Éditions du Seuil, 2000, pp. 216-8 e 2245.

${ }^{33}$ O Regulamento Processual do TPI avançou muito a operacionalização da reparação perante o TPI, com as Regras 94 (procedimento sob pedido), 95 (procedimento de ofício pelo Tribunal), 96 (publicação dos procedimentos de reparação), 97 (solicitação de reparação), 98 (Fundo de Reparação às Vítimas) e 99 (cooperação e medidas de proteção). Entre as virtudes dessa regulação está a noção de vítima (individual ou coletiva) e fixação de princípios para a reparação (individual ou coletiva).

${ }^{34}$ FRIMAN, Hakan; LEWIS, Peter. Reparation to victims. In LEE, Roy (ed.). The International Criminal Court: elements of crimes and rules of procedure and evidence. Ardsley: Transnational Publishers, 2001, p. 487
} 
por processo penal, já que as provas são destinadas à responsabilidade individual, apesar delas constituírem reflexo do coletivo. Para ela, a história somente será mais bem "pintada" por comissões de verdade fundadas em participação popular".

28. Além de apoiar o TPI e auxiliar seu sistema de cooperação penal e de reparação às vítimas, a ONU pode catalisar Comissões de Verdade, como o fez em El Salvador. Essas Comissões já foram criadas em vários países e de diversas maneiras, mas sem dúvida o substrato inicial de seu modelo de justiça é a verdade ${ }^{36}$, que está intimamente ligada à memória. Na Grécia antiga, a verdade, ou alitea, era a oposição do esquecimento (Léthe), ou seja, aproximava-se da noção da memória, que era uma divindade, a Mnemosýne. ${ }^{37} \mathrm{E}$ a verdade dessas Comissões possui mais a função de construção da memória coletiva do que se oporem à mentira. Entretanto, os modelos das Comissões da Verdade podem contrastar com a realização da justiça internacional da Corte Interamericana de Direitos Humanos ou do Tribunal Penal Internacional. Por exemplo, quando em nome da verdade revelada concede-se anistia, como se fez na África do Sul ${ }^{38}$.

29. Na realidade, autores como Paul van Zyl argumentam que pouquíssimo responsáveis pelo apartheid poderiam ser, de fato, julgados, devido a falhas do sistema judicial sulafricano, dificuldades probatórias, custos altos e tempo prolongado. Diante essas circunstâncias, a Comissão de Verdade na África do Sul seria para ele, na realidade,

\footnotetext{
${ }^{35}$ BOOTH, Cherie. Prospects and issues for the International Criminal Court: lessons from Yugoslavia and Rwanda. In SANDS, Philippe. From Nuremberg to the Hague. Cambridge: Cambridge University Press, 2003, pp. 183-184.

${ }^{36} \mathrm{Na}$ Comissão de Verdade da África do Sul, foram feitas 120 audiências públicas, quando foram ouvidos quatro mil testemunhos; apontou responsabilidades em sentido amplo, examinando o papel de várias profissões e instituições na prática de abuso de direitos humanos; recolheu 22 mil declarações de abuso por parte de vítimas; coletou provas significativas do destino das pessoas mortas ou desaparecidas, em especial mediante o procedimento da confissão em troca da anistia. Ver ZYL, Paul van. Dilemmas of Transitional Justice: the case of South Africa's Truth and Reconciliation Commission. In Journal of International Affairs, New Youk, Spring 1999, 52, n.2, p. 657.

${ }^{37}$ Vernant destaca a discussão sobre a memória endeusada entre os gregos e transtemporal, contrastada ao esquecimento e associada à verdade, textus: "Não se admirará, pois, de encontrar, no oráculo de Lebadéia, onde se mirava no antro de Trofônio uma descida ao Hades, Léthe, Esquecimento, associada a Mnemosýne e formando com ela um par de forças religiosas complementares. Antes de penetrar na boca do inferno, o consultante, já submetido aos ritos purificatórios, era conduzido para perto das duas fontes chamadas Léthe e Mnemosýne. Ao beber da primeira, ele esquecia tudo da sua vida humana e, semelhante a um morto, entrava no domínio da Noite. Pela água da segunda, ele devia guardar a memória de tudo o que havia visto e ouvido no outro mundo. À sua volta, ele não se limitava mais ao conhecimento do momento presente; o contato com o além lhe havia trazido a revelação do passado e do futuro." VERNANT, Jean-Pierre. Mito e pensamento entre os gregos. Rio de Janeiro: Paz e Terra, 1988, p. 144.

${ }^{38}$ Foi criada pelo Promotion of National Unity and Reconciliation act (1995). Foi composta por 17 membros e tinha os seguintes objetivos: traçar panorama sobre as causas, natureza e extensão das graves violações ocorridas entre $1^{\circ}$ de março de 1960 e 10 de maio de 1994; descobrir o destino ou sorte das vítimas dessas violações; oportunizar a restauração da dignidade das vítimas, possibilitando-as testemunhar sobre a violação contra seus entes queridos ou contra si; recomendar medidas de reparação ou reabilitação; garantir anistia a pessoas que declarassem por completo seus crimes; recomendar criação de instituições para gerar vida social justa e estável, bem como apontar medidas legislativas e administrativas para evitar comissão de violações similares; por fim, elaborar e publicar relatório sobre o trabalho e conclusões da Comissão.
} 
tentativa de restaurar o equilíbrio moral no processo de anistia. ${ }^{39}$ Além disso, pontua que a anistia não era absoluta, pois, para ser concedida, dependia de várias condições: ser o crime associado a objetivos políticos; o criminoso revelar a verdade por completo; ser membro de organizações políticas, movimentos de libertação ou membro das forças de segurança estatais; não ter agido para obter lucro, exceto na qualidade de informante; não ter sido o crime motivado por ódio ou maldade pessoal. Em situação de grave violação aos direitos humanos, o Comitê de Anistia promovia audiência pública para conceder anistia; e, em qualquer caso, o nome do criminoso e as informações sobre sua conduta eram publicadas no diário oficial da África do $\mathrm{Sul}^{40}$.

30. A reparação promovida por Comissão de Verdade pode ser bastante diversificada, mas sem dúvida destaco a construção coletiva da memória e suas consequiências. Conforme Paul von Zyl menciona, conhecer a verdade sobre as violações de direitos humanos e construir consenso nacional no sentido da ilegitimidade de tais atos são essenciais para prevenir sua reincidência ${ }^{41}$. Portanto, o autor associa a verdade ao tema da não repetição, mas não reduz esta àquela, pois outras medidas são tomadas para esse fim (capacitação de agentes de segurança, ensino de direitos humanos, reparação simbólica como novo funeral de algumas vítimas e construção de monumentos, desprestígio dos responsáveis e seu afastamento de cargos públicos).

31. De qualquer forma, a reparação está associada com a reconciliação, mas não está somente condicionada à verdade, pois concorrem, na perspectiva reparatória, outras formas de sanar as conseqüências da violação, a necessidade de indenizações, restitutio in integrum, quando possível, e reformas estruturais. Na África do Sul, por exemplo, uma das principais críticas à Comissão de Verdade e de Reconciliação foi sua falha em garantir devida e ampla reparação às vítimas.

32. Igualmente não se pode ignorar a importância da responsabilidade penal dos grandes responsáveis pelos crimes do regime anterior, que pode ser auxiliada ou não pela Comissão de Verdade. Nessa esteira, a ONU deve apoiar o Tribunal Penal Internacional, conforme assinala citado relatório de seu Secretário Geral. Essa perspectiva do Secretário Geral da ONU, em parte, está consagrada no acordo de relacionamento e cooperação entre o TPI e a ONU, concluído em junho de 2004. Por esse acordo, há previsão de troca de informações, assistência judiciária e cooperação sobre questões técnicas e de infraestrutura. Pelo art. $2^{\circ}$ desse acordo, a ONU reconhece o TPI como instituição judicial permanente independente, com personalidade jurídica própria e capacidade jurídica para realizar seus objetivos (art. 2.2). Simultaneamente (art. 2.1), o TPI reconhece as responsabilidades da ONU nos termos de sua Carta.

\footnotetext{
${ }^{39}$ ZYL, Paul van. Dilemas of Transitional Justice: the case of South Africa's Truth and Reconciliation Commission. In Journal of International Affairs, New Youk, Spring 1999, 52, n.2, p. 653.

${ }^{40}$ ZYL, Paul van. Dilemas of Transitional Justice: the case of South Africa's Truth and Reconciliation Commission. In Journal of International Affairs, New Youk, Spring 1999, 52, n.2, p. 655-6.

${ }^{41}$ ZYL, Paul van. Dilemas of Transitional Justice: the case of South Africa's Truth and Reconciliation Commission. In Journal of International Affairs, New Youk, Spring 1999, 52, n.2, p. 658.
} 
33. Entretanto, não se pode ignorar que os Estados Unidos tem feito campanha contrária ao TPI e pode frustrar avanços do combate à impunidade. Essa ação estadunidense contra o TPI pode ser resumida por quatro caminhos: pressionar determinado Estado para não ratificar o Estatuto de Roma; promover resolução do Conselho de Segurança para que conceda imunidades às tropas de Estados não Partes do Estatuto de Roma, como é o caso dos Estados Unidos, em missões estabelecidas ou autorizadas pela ONU (resoluções do Conselho de Segurança $\mathrm{n}^{\mathrm{os}}$ 1422, de 2002; 1487, de 2003; 1497, de 2003; e 1593, de 2005), com base equivocada no art. 16 do Estatuto de Roma; ameaçar com legislação interna proteção irrestrita ao pessoal estadunidense, inclusive com previsão de resgate de indivíduos em outro país (e.g., o American Servicemenbers' Protection Act); e celebrar acordos bilaterais com Estados evitando a entrega de seus nacionais, com base no art. 98, $\$ 2^{\circ}$, do Estatuto de Roma. A oposição dos Estados Unidos ao Tribunal Penal Internacional faz parte de doutrina ${ }^{42}$ de segurança nacional de não admitir controle multilateral sobre julgamento de seus nacionais, além de ser justificada por temor sobre futura definição do crime de agressão.

34. Portanto, a ONU cede à pressão estadunidense e frustra parcialmente pretensões de justiça internacional universal. Apesar disso, o Estatuto de Roma já conta com 100 Estados Partes e a ONU, em muitos momentos, dá sinais de estímulo à justiça internacional. Como exemplo, pode ser ressaltado que o recente Estatuto do Tribunal para Serra Leoa, em seu art. 10, não reconhece anistia para crimes contra a humanidade, violações ao art. $3^{\circ}$ comum às quatro Convenções de Genebra de 1949 e ao seu Protocolo Adicional II de 1977, e outras violações graves ao direito internacional humanitário. Importa recordar que tal art. 10 é fruto da recusa, pelo representante especial do Secretário-Geral das Nações Unidas, de poder a anistia prevista pelo Acordo de Lomé, de 1999, ser aplicada a genocídio, crimes contra a humanidade, crimes de guerra e outras violações sérias de direito internacional humanitário. ${ }^{43}$ Entendeu-se que tal anistia se referia somente a delitos prescritos pelo direito interno.

\section{Considerações finais}

35. Jon Elster caracteriza o "direito" da justiça transicional como aquele cuja intensidade da demanda por retribuição aumenta com o intervalo de tempo entre a violação e a transição e entre esta o julgamento ${ }^{44}$. Com base em experiências históricas, Jon Elster procura definir qual seria o papel dessa "justiça", o que inicialmente o faz na perspectiva de sua motivação e de suas instituições.

36. As motivações da justiça para Elster baseiam-se no trinômio razão, interesse e emoção, a serem considerados entre os atores de determinada sociedade sob diversas

\footnotetext{
${ }^{42}$ Ver SEWALL, Sarah B.; KAYSEN, Carl (ed.). The United States and the International Criminal Court: national security and international law. Lanham: Rowman \& Littlefield Publishers, inc., 2000.

${ }^{43} \mathrm{O}$ Conselho de Segurança das Nações Unidas endossaram expressamente essa posição. Veja, por exemplo, a res. 1315, de 14 de agosto de 2000.

44 ELSTER, Jon. Closing the books: transitional justice in historical perspective. Cambridge: Cambridge University Press, 2004, p. 77.
} 
formas de equilíbrio entre tais fatores ou vistos de modo hierarquizados ${ }^{45}$. Entretanto, as motivações são complexas entre os agentes da justiça transicional, pois eles podem acumular funções contraditórias no processo histórico ${ }^{46}$. No regime político a ser superado, vários agentes são identificados: como os culpados, as vítimas, os beneficiários do ilícito, os que socorrem, os que resistem e os neutros. Após esse regime, surgem os promotores e os defensores da justiça transicional, bem como os que a ela resistem. Elster identifica onze situações de confusão entre esses papéis concentrados no mesmo indivíduo $^{47}$, o que torna discussão não somente da motivação desses atores, mas o compromisso na construção da memória individual e da memória coletiva bastante intrincado.

37. Do ponto de vista institucional, haveria três tipos de justiça: a política, a legal e a administrativa $^{48}$. A justiça política seria aquela que o novo governo define quem são os culpados e o que se deve fazer com eles. A justiça legal é definida por quatro características: a definição e clareza da norma, a independência do judiciário, a imparcialidade dos julgadores e o devido processo legal. E a justiça administrativa é a realizada pela administração pública, similar à legal, que permite recurso.

38. Os teóricos como Elster e Teitel, entre outros, possuem visão bastante hermética da justiça transicional, embora tenham traçado muitas vezes perspectivas históricas e identificado vários fatores locais que dificultam a consolidação eficaz dessa justiça. Faltalhes, entretanto, teorização das peculiaridades locais no sentido de entender o esperado pelas vítimas de determinada comunidade em relação ao sofrido concretamente, seja a segregação, a tortura, a violação sexual, o desaparecimento de familiar, etc. A ONU e sua burocracia, muitas vezes, incorre no mesmo erro quando tenta impulsionar processos locais de justiça e reconciliação.

39. De fato, o desafio é grandioso, afinal conciliar normas universais com expectativa doméstica não é tarefa fácil ${ }^{49}$. Particularmente creio que são algumas normas universais que garantem a sobrevivência da comunidade, como as que proíbem o genocídio ou definem os direitos religiosos e culturais, mas há limites e conflitos nessa definição normativa. À comunidade, também, é salutar o contraste e a autocrítica, bem como o direito de resolver problemas internos primariamente. Hoje, o direito internacional penal consagra o Estado como o grande responsável para julgar os crimes considerados como internacionais (genocídio, crimes contra a humanidade e crimes de guerra), cometidos gravemente. Esse direito estatal possui significativa liberdade em matéria de penas,

\footnotetext{
${ }^{45}$ ELSTER, Jon. Closing the books: transitional justice in historical perspective. Cambridge: Cambridge University Press, 2004, p. 79 e seguintes.

${ }^{46}$ ELSTER, Jon. Closing the books: transitional justice in historical perspective. Cambridge: Cambridge University Press, 2004, p. 99 e seguintes.

47 Beneficiário do ilícito/resistente; resistente/culpados; vítima/culpado; culpados/beneficiários; neutro/culpado/resistente; vítima/resistente; vítima/promotores da justiça; resistente/promotores; neutros/promotores; beneficiários/resistentes; beneficiários/promotores.

${ }^{48}$ ELSTER, Jon. Closing the books: transitional justice in historical perspective. Cambridge:

Cambridge University Press, 2004, p. 84 e seguintes.

${ }^{49}$ Ver CRONIN, Ciaran; DE GREIFF, Pablo. Global Justice and Transnational Politcs. Massachusetts: MIT Press, 2002.
} 
perdões, absolvições e procedimentos. Entretanto, o Estado, muitas vezes, é o grande algoz de seus próprios nacionais ou de estrangeiros, o que torna a justiça internacional debate imprescindível para quem se preocupa com a defesa da dignidade humana. 